TITLE:

\title{
Interaction of wheat $\beta$-amylase with maltose and glucose as examined by fluorescence.
}

\section{$\operatorname{AUTHOR}(\mathrm{S}):$}

Daba, Tadessa; Kojima, Kenji; Inouye, Kuniyo

\section{CITATION:}

Daba, Tadessa ... [et al]. Interaction of wheat $\beta$-amylase with maltose and glucose as examined by fluorescence... Journal of biochemistry 2013, 154(1): 85-92

ISSUE DATE:

2013-07

URL:

http://hdl.handle.net/2433/189714

\section{RIGHT:}

This is a pre-copyedited, author-produced PDF of an article accepted for publication in "Journal of Biochemistry" following peer review. The version of record "Tadessa Daba, Kenji Kojima, and Kuniyo Inouye; Interaction of wheat $\beta$ amylase with maltose and glucose as examined by fluorescence; J Biochem (2013) 154 (1): $85-92$ first published online April 16, 2013 doi:10.1093/ib/mvt029" is available online at:http://jb.oxfordjournals.org/content/154/1/85; This is not the published version. Please cite only the published version.; この論文は出版社版でありません。引用の際には出版社 版をご確認じ利用ください。 


\section{Journal of Biochemistry}

Regular paper; Field: Biochemistry - Enzymology

\section{Interaction of Wheat $\beta$-Amylase with Maltose and Glucose as Examined by Fluorescence}

Tadessa Daba, Kenji Kojima, and Kuniyo Inouye*

Division of Food Science and Biotechnology, Graduate School of Agriculture, Kyoto

University, Sakyo-ku, Kyoto 606-8502, Japan

Running Head:

Interaction of wheat $\beta$-amylase with maltose and glucose

*To whom correspondence should be addressed. Tel: +81-75-753-6266

Fax: +81-75-753-6265, E-mail: inouye@kais.kyoto-u.ac.jp (K. Inouye)

Abbreviations: AU, arbitrary unit; BA, $\beta$-amylase; BacBA, Bacillus $\beta$-amylase; BBA, barley $\beta$-amylase; EI, enzyme-inhibitor complex; $\mathrm{p} I$, isoelectric point; SBA, soybean $\beta$-amylase; WBA, wheat $\beta$-amylase 


\section{ABSTRACT}

Fluorescence of wheat $\beta$-amylase (WBA) was quenched by the interaction with maltose or glucose, which are competitive inhibitors of WBA, suggesting that the states of tryptophan and tyrosine residues could be changed by the interaction. The fluorescence emitted by excitation at $280 \mathrm{~nm}$ and $295 \mathrm{~nm}$ was titrated by changing the concentrations of maltose and glucose. The dissociation constant $\left(K_{\mathrm{d}}\right)$ values of the WBA-maltose and WBA-glucose complexes were determined to be $0.20 \pm 0.12 \mathrm{M}$ for maltose and $0.36 \pm$ $0.11 \mathrm{M}$ for glucose at $25^{\circ} \mathrm{C}$, $\mathrm{pH}$ 5.4. Maltose exhibited additional binding mode at higher concentration with a distinct $K_{\mathrm{d}}$ value $(1.5 \pm 0.4 \mathrm{M})$. The $K_{\mathrm{d}}$ values at various temperatures and $\mathrm{pHs}$ are in agreement with the inhibitor constant $\left(K_{\mathrm{i}}\right)$ values previously reported. The negative standard enthalpy changes $\left(\Delta H^{\circ}\right)$ of the WBA association with glucose and maltose indicate that the associations are exothermic. The association constant $\left(K_{\mathrm{a}}\right)$ and $\Delta G^{\mathrm{o}}$ values of the maltose and glucose binding to WBA decreased slightly with increasing temperature from 25 to $45^{\circ} \mathrm{C}$ but not dependent on $\mathrm{pH}$ change (pH 3.0, 5.4 and 9.0). Fluorescence of WBA could be used as a structural probe to examine the inhibitory interaction with the products of starch hydrolysis.

Keywords: dissociation constant; fluorescence quenching; glucose; maltose; wheat $\beta$-amylase. 


\section{INTRODUCTION}

$\beta$-Amylases ( $\alpha$-1,4-glucan maltohydrolases; abbreviated as BA hereinafter) are exo-acting enzymes, with successive removal of $\beta$-anomeric maltose from the non-reducing ends of polysaccharides. BAs are found in higher plants and some microorganisms but there are variations between bacterial and plant $\beta$-amylases in binding and hydrolyzing raw starch (1). This binding aptitude difference is credited to their starch-binding domain located at the C-terminus of their sequence (2). The subsite affinities of wheat $\beta$-amylase (hereinafter designated as WBA) (3) and soybean $\beta$-amylase (SBA) (4) were described. Subsite 1 has the highest affinity to glucose residues of the substrates among the five subsites in WBA and this subsite has a vital role in its catalytic activity (3). The crystal structures of maltose binding sites in SBA (5) and in Bacillus $\beta$-amylase (BacBA) (6) were also reported. Understanding the subsite structure of enzymes helps to predict the binding modes of substrates (7), and a glutamate residue was identified as the possible catalytic residue of soybean and sweet potato $\beta$-amylases $(8,9)$.

The inhibitory effects of glucose $(7)$, maltose $(7,10)$, and cyclohexa-amylose $(11,12)$ on BAs were studied. We have recently reported the inhibitory effects of maltose, glucose, and sugar derivatives on the catalytic activity of WBA (13). Formerly, we have also described the activation and thermo-stabilization effects of additives (carbohydrates, amino acids, organic solvents, proteins, detergents, etc.) on WBA and indicated the possibility of altering the stability and activity by modification of the enzyme reaction system 
(14).

Temperature has substantial effect on the molecular activity as well as conformation of enzymes. The inhibitor constant $\left(K_{\mathrm{i}}\right)$ values of inhibitors were affected by changes in temperature $(15,16)$. pH alters the ionization of the functional groups and conformation of enzymes and hence might affect the substrate or inhibitor binding. The effects of temperature and $\mathrm{pH}$ on the $K_{\mathrm{i}}$ and thermodynamic parameters of glucose and maltose inhibitions were described previously in our inhibition study of WBA by maltose and glucose (13).

The fluorescence change of enzymes could be a good probe for examining the binding of substrates or inhibitors (17). The states of tryptophan and tyrosine residues of BacBA were affected up on binding glucose or maltose (5-7). Gluconolactone and maltose were reported to quench the fluorescence of glucoamylase (18). A small change in the catalytic residue of subtilisin (Ser221 to Cys221) led to considerable decrease in its binding affinity to Streptomyces subtilisin inhibitor (19). In the present study, we describe the WBA fluorescence quenching effects of glucose and maltose, the temperature and $\mathrm{pH}$-dependences of the association constant $\left(K_{\mathrm{a}}\right)$ of the association of WBA with the inhibitors and thermodynamic parameters. This study provides valuable information on the interaction of the end-products of starch hydrolysis with WBA and its effect on the tryptophan and tyrosine residues of WBA. The changes in the states of tryptophan and tyrosine residues of WBA are associated with the change in its activity by the interaction with maltose or glucose. 


\section{MATERIALS AND METHODS}

Materials - A commercial preparation of WBA, Himaltosin GS (Lot 2S24A), was purchased from HBI Enzymes (Osaka, Japan). WBA was purified from the Himaltosin preparation according to the method described previously (14) to homogeneity in polyacrylamide-gel electrophoresis (SDS-PAGE) with a molecular mass of $57.7 \mathrm{kDa}$. The stabilizer starch contained in the Himaltosin preparation was completely removed by filtration through Millipore membrane filter (Type HA; pore size: $0.45 \mu \mathrm{m}$ ) as confirmed by starch-iodine reaction (14). The concentration of WBA was determined spectrophotometrically in $20 \mathrm{mM}$ sodium acetate buffer, $\mathrm{pH} 5.4$ (hereinafter designated as buffer $\mathrm{A}$ ) at $25^{\circ} \mathrm{C}$ using the absorptivity value $(A)$ of $1.40 \pm 0.02$ at $281 \mathrm{~nm}$ with a 1.0-cm light-path for $1.0 \mathrm{mg} / \mathrm{ml}$ of WBA solution (14). Maltose (Lot M1B6462), glucose (Lot M3G8543), and N-acetyl-L-tryptophan-ethyl ester (AWEE, Lot V6P4299) were purchased from Nacalai Tesque (Kyoto, Japan), $N$-acetyl-L-tyrosine-ethyl ester (AYEE, Lot 41666/1 42901) was from Fluka chemicals (Buchs SG, Switzerland) and other chemicals were from Wako Pure Chemical (Osaka, Japan).

Fluorometric titration of WBA with maltose and glucose - WBA in buffer A was filtered through a Millipore membrane filter (Type HA; pore size: $0.45 \mu \mathrm{m}$ ) and twice through a Sephadex G-25 column equilibrated with the same buffer. The initial concentration of WBA was adjusted to $0.2 \mu \mathrm{M}$. Various initial concentrations of maltose $(0-1.4 \mathrm{M})$ and glucose $(0-2.8 \mathrm{M})$ were also prepared in buffer $\mathrm{A}$. The 
fluorescence titration of the enzyme with increasing concentrations of maltose and glucose was carried out using a Shimadzu RF-5300PC spectrofluorometer (Kyoto, Japan) at $25^{\circ} \mathrm{C}$ with an excitation wavelength $280 \mathrm{~nm}\left(\lambda_{\mathrm{ex}}=280 \mathrm{~nm}\right)$, with a high sensitivity and a response time of $4 \mathrm{~s}$. The solvent perturbation effect on tryptophan and tyrosine was examined using 5.5 $\mu \mathrm{M}$ AWEE and 7.4 $\mu \mathrm{M}$ AYEE in the presence and absence of various concentrations of maltose or glucose.

The tryptophan fluorescence of WBA - The contributions of tryptophan and tyrosine residues in the fluorescence emission of WBA and how the fluorescence of tryptophan is quenched by maltose and glucose were studied. WBA $(0.2 \mu \mathrm{M})$ was prepared in buffer $\mathrm{A}$ at $25^{\circ} \mathrm{C}$. The fluorescence spectra was collected in the range of 308-450 $\mathrm{nm}$ at $\lambda_{\mathrm{ex}}=280 \mathrm{~nm}$ and at $\lambda_{\mathrm{ex}}=295 \mathrm{~nm}$, with a high sensitivity and a response time of $4 \mathrm{~s}$. The fluorescence intensity of WBA in the absence and presence of high initial concentrations of maltose $(1.4 \mathrm{M})$ and glucose $(2.8 \mathrm{M})$ at $\lambda_{\mathrm{ex}}=295 \mathrm{~nm}$ were examined.

Temperature-dependence of $K_{\mathrm{d}}$ - Various initial concentrations of maltose (0-1.4 M) and glucose (0-2.8 M) were prepared in buffer $\mathrm{A}$ at $25^{\circ} \mathrm{C}$. The inhibitors were kept in water bath adjusted at each temperature and the enzyme solution was kept in ice water. The enzyme solution was incubated in a water bath at each temperature for $3 \mathrm{~min}$ and mixed in a cuvette with the inhibitors, and the fluorescence spectra were collected after 2 min at the same temperature. Only low concentrations (0-1 M) of both maltose and 
glucose were considered to determine the $K_{d}$ values at 35 and $45^{\circ} \mathrm{C}$, pH 5.4. The hyperbolic relationship of the change in fluorescence $(\Delta F)$ against the inhibitor concentration was converted to linear correlation so that the experimental data were fitted to linear plot using the least-squares regression method following previous report (18). The $K_{d}$ values at each temperature were estimated using Hanes-Woolf plots $(18,20)$. The standard enthalpy changes $\left(\Delta H^{\circ}\right)$ of maltose and glucose binding to WBA were determined by the van't Hoff equation (Eq. 1).

$$
\ln K_{\mathrm{d}}=\left(\Delta H^{\circ} / R\right)(1 / T)-\Delta S^{\circ} / R
$$

The Gibbs energy change $\left(\Delta G^{0}\right)$ and entropy change $\left(\Delta S^{\circ}\right)$ were derived from Eqs. 2 and $3(21,22)$.

$$
\begin{aligned}
& \Delta G^{0}=-R T \ln K_{\mathrm{d}} \\
& T \Delta S^{0}=\Delta H^{\mathrm{o}}-\Delta G^{\mathrm{o}}
\end{aligned}
$$

where $R$ is the universal gas constant and $T$ is the absolute temperature.

pH-dependence of $K_{\mathrm{d}}$ - The WBA and inhibitors (0-1 M) solutions were prepared in various buffers at $25^{\circ} \mathrm{C}$, namely $20 \mathrm{mM}$ sodium acetate at pH 5.4 (buffer A), $20 \mathrm{mM}$ glycine- $\mathrm{HCl}$ at $\mathrm{pH}$ 3.0, and $20 \mathrm{mM}$ borate buffer at pH 9.0. The procedure aforementioned was followed to obtain the $K_{\mathrm{d}}$ values at various pHs. 


\section{RESULTS}

Quenching the fluorescence of WBA by maltose and glucose - The fluorescence of WBA was partially quenched by increasing concentrations of maltose and glucose at $25^{\circ} \mathrm{C}, \mathrm{pH} 5.4$. The changes in the maximum fluorescence $\left(\Delta F_{\max }\right)$ of WBA were $13 \%$ and $15 \%$ of the fluorescence intensity observed in the absence of inhibitor, respectively by the addition of $1.4 \mathrm{M}$ maltose and by the addition of $2.8 \mathrm{M}$ glucose (Fig. 1). The effects of increasing concentrations of maltose and glucose on the fluorescence of tryptophan and tyrosine were examined by fluorescence titration of model compounds, AWEE and AYEE. The net effects of increasing concentrations of the sugars were negligible $(<2 \%)$ in AWEE and $<4 \%$ in AYEE. The decrease in the fluorescence intensity of WBA by the titration with increasing maltose or glucose concentrations shows that the fluorescence of WBA is quenched by the interaction with maltose or glucose.

Fig. 1

Quenching the fluorescence of WBA by concentrations of maltose up to $1.4 \mathrm{M}$ and glucose up to

2.8 $\mathrm{M}$ were examined at $25^{\circ} \mathrm{C}, \mathrm{pH} 5.4$. The change in fluorescence $(\Delta F)$ is the difference between the fluorescence intensity $(F I)$ of WBA in the absence of inhibitor ( $F_{\max }$ WBA + buffer) minus the FI of WBA 
in the presence of inhibitors $\left(F_{\max } \mathrm{WBA}+\right.$ inhibitors). It shows the change in fluorescence of WBA due to the interaction with increasing concentrations of maltose or glucose. The Michaelis-Menten-type relationships of $\Delta F$ vs. [I] plots were shown (Fig. 2A). The fluorescence of WBA was partially quenched in a dose-dependent manner with increasing concentrations of maltose or glucose.

Fig. 2

The plots of $\Delta F$ against lower inhibitor concentrations (0-1 M) obey a Michaelis-Menten-type relationship at all temperatures and $\mathrm{pHs}$ examined. Thus this relationship was treated using the following equilibrium based on previous report (18):

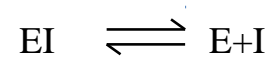

where E, I, and EI represent the enzyme; inhibitor; and enzyme-inhibitor complex, respectively. In conditions where the enzyme concentration [E] is negligible compared to the inhibitor concentrations [I], it can be written as:

$$
[\mathrm{EI}]=[\mathrm{E}]_{\mathrm{t}}[\mathrm{I}] /\left(K_{\mathrm{d}}+[\mathrm{I}]\right)
$$

where $K_{\mathrm{d}}$ is the dissociation constant of the EI complex and $[\mathrm{E}]_{\mathrm{t}}$, is the total enzyme concentration. By considering that $\Delta F$ is proportional to [EI] (18), it can be rewritten in a linear form:

$$
[\mathrm{I}] / \Delta F=\left(K_{\mathrm{d}} / \Delta F_{\max }\right)+\left([\mathrm{I}] / \Delta F_{\max }\right)
$$


where $\Delta F_{\max }$ is the maximum decrease in fluorescence observed when the enzyme is saturated by maltose or glucose. The validity of equation (5) is confirmed by the linearity of the Hanes-Woolf plot ([I]/ $\Delta F$ vs. [I] plot) (Fig. 2B). The Hanes-Woolf plot for maltose concentration range (0-1.4 M) up to its higher concentration resulted in a higher $K_{\mathrm{d}}$ value $(0.5 \pm 0.6 \mathrm{M})$ with a larger standard deviation (SD) by considering that the binding of WBA and maltose was estimated by Eq. (4). We considered the possibility that the binding is composed of two modes with two $K_{\mathrm{d}}\left(K_{\mathrm{d} 1}\right.$ and $\left.K_{\mathrm{d} 2}\right)$ values (Fig. 2B). The lower concentration $(0-1 \mathrm{M})$ of maltose showed a smaller $K_{\mathrm{d}}$ value $(0.2 \pm 0.1 \mathrm{M})$, which is similar to the $K_{\mathrm{i}}$ value, with a smaller SD. The binding of this lower concentration (0-1 M) of maltose is corresponding to the inhibitory binding to the active site of WBA. We have previously reported the inhibition of WBA activity by lower concentrations of maltose $(0-0.2 \mathrm{M})$ and glucose $(0-0.5 \mathrm{M})(13)$. The higher maltose concentration (1.1-1.4 M) gave a higher $K_{\mathrm{d}}$ value $(1.5 \pm 0.4 \mathrm{M})$ (Fig. 2B) suggesting secondary binding to WBA. Assuming that $K_{\mathrm{d} 2} \gg K_{\mathrm{d} 1}$ and $[\mathrm{I}]>>K_{\mathrm{d} 1}$,

$$
[\mathrm{I}] / \Delta F=[\mathrm{I}]\left(K_{\mathrm{d} 2}+[\mathrm{I}]\right) /\left(\Delta F_{1} K_{\mathrm{d} 2}+\left(\Delta F_{1}+\Delta F_{2}\right)[\mathrm{I}]\right.
$$

This indicates that the extrapolation of the straight line at high concentrations of [I] will intersect the abscissa at $[\mathrm{I}]=-K_{\mathrm{d} 2}$. The dotted lines in Fig. 2B were fitted to the data obtained using the concentrations of maltose $>1 \mathrm{M}$. In the case of glucose, all the evaluated concentrations exhibited good regression $\left(\mathrm{R}^{2}=\right.$ 0.99) from the single linear fitting with the $K_{\mathrm{d}}$ value of $0.3 \pm 0.1 \mathrm{M}$, which is in good agreement with the $K_{\mathrm{i}}$ values. Glucose binds to the active site of WBA as a competitive inhibitor in the range of 0-2.8 M. Maltose 
binds to the active site as a competitive inhibitor in the range of $0-1 \mathrm{M}$ and binds to the secondary binding site of WBA in the range of 1.1-1.4 M.

Tryptophan fluorescence of WBA - The florescence emission of WBA due to its tryptophan and tyrosine residues was examined by changing the excitation wavelength from $280 \mathrm{~nm}$ to $295 \mathrm{~nm}$ (Fig. 3A). The fluorescence of WBA at $\lambda_{\mathrm{ex}}=295 \mathrm{~nm}$ was quenched up to $8 \%$ by $1.4 \mathrm{M}$ maltose and $9 \%$ by $2.8 \mathrm{M}$ glucose (Fig. 3B). The Michaelis-Menten-type plots (Fig. 4A) are the $\Delta F$ of WBA observed by fluorescence titration of WBA with maltose and glucose at $\lambda_{\mathrm{ex}}=295 \mathrm{~nm}$. The $K_{\mathrm{d}}$ values of maltose $(0.3 \pm 0.0 \mathrm{M})$ and glucose $(0.5 \pm 0.1 \mathrm{M})$ in quenching the tryptophan fluorescence were determined at $25^{\circ} \mathrm{C}, \mathrm{pH} 5.4$ (Fig. 4B). The $\Delta F$ at $\lambda_{\mathrm{ex}}=295 \mathrm{~nm}$ with increasing concentrations of maltose and glucose indicates that the fluorescence of WBA due to its tryptophan residues was quenched by the interaction of WBA with maltose and glucose. It may be due to the change in the states of tryptophan residues of WBA to less hydrophobic conditions by the interaction with maltose and glucose.

Fig. 3

Fig. 4 
Temperature-dependence of $K_{\mathrm{d}}$ - The fluorescence of WBA reduced by about $20 \%$ with increasing temperature from 25 to $45^{\circ} \mathrm{C}$. The respective $K_{d}$ values of the WBA-maltose and WBA-glucose dissociations of lower concentrations (0-1 M) of maltose or glucose were estimated from the Hanes-Woolf plots at 35 , and $45^{\circ} \mathrm{C}$, at $\mathrm{pH} 5.4$ (Fig. 5). These plots were derived from the $\Delta F$ of WBA with increasing concentrations of maltose or glucose according to Eq. 5. The $K_{\mathrm{d}}$ values of the WBA-maltose or WBA-glucose dissociations increased slightly with increasing temperature from $25^{\circ} \mathrm{C}$ to $45^{\circ} \mathrm{C}$ (Table 1 ). The $K_{\mathrm{a}}$ values were $5.0 \pm 1.1,3.2 \pm 0.8$, and $2.7 \pm 0.9 \mathrm{M}^{-1}$ for maltose and $2.8 \pm 0.9,2.4 \pm 0.9$, and $2.2 \pm$ $0.7 \mathrm{M}^{-1}$, respectively at $25^{\circ} \mathrm{C}, 35^{\circ} \mathrm{C}$ and $45^{\circ} \mathrm{C}$, at $\mathrm{pH} 5.4$. Temperature is suggested to affect the molecular activity and the conformation of enzymes and hence it slightly affected the $K_{\mathrm{d}}$ and consequently the $K_{\mathrm{a}}$ values.

Fig. 5

Table 1

The thermodynamic parameters $\left(\Delta G^{0}\right.$ and $\left.\Delta S^{\circ}\right)$ of the binding of WBA with maltose or glucose were slightly affected by a change in temperature. The $\Delta G^{\mathrm{o}}$ and $K_{\mathrm{a}}$ values were found to decrease in magnitude with increasing temperature (Table 1). The $\Delta G^{0}$ values were changed from $-4.0 \pm 0.8$ to $-2.5 \pm 0.8 \mathrm{~kJ} \mathrm{~mol}^{-1}$ in the maltose binging and from $-2.5 \pm 0.9$ to $-1.9 \pm 0.7 \mathrm{~kJ} \mathrm{~mol}^{-1}$ in the glucose binding to WBA by 
changing temperature from $25^{\circ} \mathrm{C}$ to $45^{\circ} \mathrm{C}$, at $\mathrm{pH}$ 5.4. The $\Delta H^{\circ}$ values of the binding of WBA with maltose and glucose were determined from van’t Hoff plot (Fig. 6) to be $-24.3 \pm 3.2 \mathrm{~kJ} \mathrm{~mol}^{-1}$ and $-9.7 \pm 2.5 \mathrm{~kJ} \mathrm{~mol}^{-1}$, respectively.

Fig. 6

$p H$-dependence of $K_{\mathrm{d}}$ - The effects of maltose and glucose on the fluorescence of WBA was studied at three different pHs $(3.0,5.4$, and 9.0$)$ at $25^{\circ} \mathrm{C}$. The optimum $\mathrm{pH}$ for the WBA activity in starch hydrolysis is $\mathrm{pH} 5.4$ (23). The relative activity of WBA in starch hydrolysis is about $60 \%$ at $\mathrm{pH} 3.5$ and less than $10 \%$ at $\mathrm{pH} 7.5$ relative to at its optimum $\mathrm{pH} 5.4$ (23). The more acidic $\mathrm{pH}, 3.0$ and alkaline $\mathrm{pH}, 9.0$ conditions than the optimum $\mathrm{pH}, 5.4$ were considered in this study. The $K_{\mathrm{d}}$ values were determined at each $\mathrm{pH}$ from the Hanes-Woolf plots as presented in Fig. 7A at pH 3.0 and Fig. 7B at pH 9.0. The Hanes-Woolf plot at $\mathrm{pH} 5.4,25^{\circ} \mathrm{C}$ is shown in Fig. 2B. The estimated $K_{\mathrm{d}}$ values at $\mathrm{pHs} 3.0,5.4$, and 9.0 were almost the same as $0.2 \pm 0.1 \mathrm{M}$ for maltose and $0.3 \pm 0.1 \mathrm{M}$ for glucose. The $K_{\mathrm{d}}$ and $\Delta G^{\mathrm{o}}$ values at various pHs were presented in Table 2. The $\mathrm{pH}$ of a reaction affects the ionizable groups of enzymes and the polarity of the solvent environment and hence, supposed to affect the interactions of enzymes with their inhibitors or substrates. However, the $K_{\mathrm{d}}$ values did not show considerable difference due to the $\mathrm{pH}$ change examined. The $K_{\mathrm{a}}$ 
values of WBA and maltose or glucose interactions and the $\Delta G^{0}$ values were hence not affected by changing the $\mathrm{pH}$ from 3.0 to 9.0 (Table 2).

Fig. 7

Table 2

\section{DISCUSSION}

Quenching the fluorescence of WBA by maltose and glucose - The fluorescence of WBA was partially quenched by maltose and glucose. WBA (GenBank accession number X98504.1) has 10 tryptophan and 23 tyrosine residues (24). The interaction of certain amino acid residues which quench the fluorescence of tryptophan residues of SBA were affected up on binding substrates or final products (25). The variation in magnitude of $\Delta F$ depending on the size of substrates shows the presence of at least two tryptophan residues in the active site of SBA (25). The states of tryptophan and tyrosine residues of SBA were changed on the binding with cyclohexadextrin and maltose, producing characteristic difference spectra in the ultraviolet region (26). In the hydrophobic solvent environment, the fluorescence intensity of a protein increases and the intensity peak shifts to a shorter wavelength by up to $15 \mathrm{~nm}$ (27). Thus, the states of tryptophan and tyrosine residues of WBA are converted to less hydrophobic condition by the addition of maltose or glucose. Maltose and gluconolactone inhibited the fluorescence of glucoamylase (18). The positions of Thr330 and Cys331 
were altered by 1.08 and $1.14 \AA$, respectively, by binding maltose and affected the environment of tryptophan residues around the active site of BacBA (5). In addition to the movement of the flexible loop, the side chains of Tyr164 flipped by $34^{\circ}$ because of maltose binding to BacBA, and the maltose binding to its C-terminal starch-binding domain interacts with Trp449 and Trp495 (6). These lines of evidence clarify that the fluorescence of WBA could be affected by the interaction with maltose or glucose. Identifying the specific tryptophan or tyrosine residues behind the fluorescence quenching by the interaction enables better understanding the role of binding subsites of the enzyme.

Despite many similarities among plant $\beta$-amylases, microbial BAs differ considerably from plant BAs in the starch-binding domain located at their C-terminal (2). According to National Center for Biotechnology Information (NCBI) GenBank database, there are molecular distinctions even among plant BAs in the number of amino acids, molecular weight and number of Trp and Tyr residues. Using NCBI Basic Local Alignment Search Tool (BLAST), the amino acid sequence similarity of WBA is 69\% with SBA, 82\% with barley BA (BBA) and only 30\% with BacBA based on the principle reported (28). These BAs vary in enzymatic behavior such as the molecular activity $\left(k_{\text {cat }}\right)$, Michaelis constant $\left(K_{\mathrm{m}}\right)$ in hydrolyzing soluble starch under similar experimental temperature and $\mathrm{pH}$ conditions $(7,14,29)$. The $K_{\mathrm{i}}(5.8 \pm 1.1 \mathrm{mM})$ of maltose in SBA inhibition is much smaller than that in WBA inhibition $(0.2 \pm 0.0 \mathrm{M})$ while that of glucose $(320 \pm 80 \mathrm{mM})$ in SBA inhibition is in agreement with that in WBA inhibition $(0.4 \pm 0.0 \mathrm{M})$ at $\mathrm{pH} 5.4,25^{\circ} \mathrm{C}$ $(7,13)$. WBA is less in thermal stability as compared to SBA, BBA, and BacBA. The temperature at which 
they lose half of their activity after 30 incubation $\left(T_{50}\right)$ are $50^{\circ} \mathrm{C}$ for WBA $(14), 57^{\circ} \mathrm{C}$ and $63^{\circ} \mathrm{C}$ for BBA and SBA, respectively (30). Hence, it could not be possible to extrapolate the experimental result of one BA to another.

Maltose exhibited two distinct $K_{\mathrm{d}}$ values at lower (0-1 M) and higher concentrations (1.1-1.4 M) suggesting that it has two modes of binding with WBA. It appeared to bind to the active site of WBA at the lower concentrations with $K_{\mathrm{d}}$ value similar to the $K_{\mathrm{i}}$ value previously reported (13). This may be the inhibitory binding at the active site and secondary binding mode at higher (1.1-1.4 M) concentration with higher $K_{\mathrm{d}}$ value, which is supposed to be different from the active site of WBA. Glucose appeared to have single mode of biding WBA in this study. In the inhibitory binding at the active site of WBA by glucose and lower concentration of maltose, they are supposed to quench the fluorescence of tryptophan and tyrosine residues around the active sites of WBA. The most probable fluorescing residues of WBA quenched by the interaction are Trp53, Trp196, Trp299, Tyr187 and Tyr416 based on the crystal structure of WBA from SWISS-MODEL (31) using BBA template, PDB2XFR. However, crystallographic study may be required to confirm this fact and the experimental errors cannot be neglected because of handling small $\Delta F$ in this study. The subsite affinities of WBA were determined (3) following the subsite theory (32). Glucose binds to subsites 1 and 4, whereas maltose binds to subsites 1 and 2, and possibly to subsites 4 and 5 in SBA (9). In BacBA glucose binds to subsites 1 and 2 (7), and to subsites 1 , 2 or 4 in barley BA (BBA) (33). WBA has similar subsite affinities to SBA (3). Maltose is known to have the secondary binding site at about $30 \AA$ far 
from the active site, and also another binding site at domain $\mathrm{C}$ in BacBA (5, 6). Therefore, the sugars may have multiple binding modes or binding sites on $\beta$-amylases. Hence, only low concentrations of the inhibitors were considered for the estimation of $K_{\mathrm{d}}$ values in this study also based on previous recommendation (34).

The tryptophan fluorescence of WBA - The fluorescence emission of WBA due to its tryptophan residues was partially quenched by the interaction of WBA with maltose or glucose. The $K_{d}$ values of maltose $(0.3 \pm 0.0$ $\mathrm{M})$ and glucose $(0.5 \pm 0.1 \mathrm{M})$ in quenching the tryptophan fluorescence of WBA at $25^{\circ} \mathrm{C}, \mathrm{pH} 5.4$ were almost similar to their respective $K_{\mathrm{d}}$ values $0.2 \pm 0.1 \mathrm{M}$ and $0.4 \pm 0.1 \mathrm{M}$ in quenching the total fluorescence of WBA. This may also imply that quenching the fluorescence of WBA by the interaction with maltose or glucose is mainly by affecting the conditions of its tryptophan residues.

Temperature-dependence of $K_{\mathrm{d}}$ - The $K_{\mathrm{d}}$ values of the WBA-glucose and WBA-maltose dissociations were slightly affected by temperature as it influences the molecular activities of the solvent and reactants. It also affects the structure of the protein, which entails changes in enzyme-inhibitor binding or dissociation (20, 34). The $K_{\mathrm{d}}$ values in this study and the $K_{\mathrm{i}}$ values from our previous kinetic study (13) are in good agreement. A slight increase in $K_{\mathrm{d}}$ values with temperature was observed (Table 1 ). Increasing $K_{\mathrm{i}}$ values with increasing temperature were also previously reported in various enzymes $(21,22,34)$. The condition 
of the solvent environment plays a decisive role in the fluorescence intensity of proteins. An increase in UV light absorption $\left(A_{292} \mathrm{~nm}\right)$ of SBA with increasing concentration of maltose was ascribed to nonspecific solvent perturbation effect (25).

Temperature exerted slight influence on the thermodynamic parameters of maltose and glucose binding to WBA (Table 1). The $\Delta G^{\circ}$ value decreased by $1.5 \mathrm{~kJ} \mathrm{~mol}^{-1}$ in maltose and $0.6 \mathrm{~kJ} \mathrm{~mol}^{-1}$ in glucose with increasing temperature from $25^{\circ} \mathrm{C}$ to $45^{\circ} \mathrm{C}$ due to an increase in the entropy changes with increasing temperature. The negative $\Delta H^{\circ}$ shows that the bindings of maltose or glucose to WBA are exothermic and the $\Delta G^{0}$ indicates that the binding processes are spontaneous (Table 1). The crystallographic study of the binding of glucose and maltose to the active site of BacBA revealed that it is mainly by forming hydrogen-bonds (5). Higher $\Delta G^{\text {o }}$ values were obtained in maltose binding to WBA than that of glucose (Tables 1 ), which agrees with their structural compositions. One maltose molecule contains two glucose residues and binds to two subsites of WBA while one glucose molecule binds to only one subsite and hence there are more H-bonds in maltose than glucose in binding to WBA.

pH-dependence of $K_{\mathrm{d}}$ - The $K_{\mathrm{d}}$ and $\Delta G^{\mathrm{o}}$ values did not show considerable difference with change in $\mathrm{pH}$. There was redshift in $\lambda_{\max }$ of WBA fluorescence from $338 \mathrm{~nm}$ at pH 5.4 to $343 \mathrm{~nm}$ at pH 9.0 and $344 \mathrm{~nm}$ at $\mathrm{pH}$ 3.0. This is because of an exposure of the fluorescing residues of the enzyme to the polar solvent environment. The isoelectric point (pI) of WBA is 5.8 (35), which is similar to that of SBA, 5.6 (36). This 
implies that at $\mathrm{pH} 3.0$, WBA is positively charged and both glucose and maltose bind the active site in this state (13). The inhibition type depends on the binding sites of inhibitors (37). However, the $K_{\mathrm{a}}$ and thus $\Delta G^{\circ}$ values were not dependent on $\mathrm{pH}$ change from $\mathrm{pH} 3.0$ to 9.0.

In the enzymatic starch hydrolysis process, maltose and glucose are continuously produced. Studying the molecular interaction of these end-products and WBA is valuable to identify the reaction condition where the product inhibition is relatively low and seek possible mechanisms of reducing the end-product inhibition. The change in fluorescence intensity $(\Delta F)$ of WBA by maltose and glucose showed that the tryptophan and tyrosine environments around its binding sites are affected as the result of binding the sugars. Quenching the fluorescence of WBA with maltose or glucose may be mainly by affecting the states of tryptophan residues. Maltose is suggested to have two binding modes to WBA at low and higher concentrations. The $K_{\mathrm{a}}$ and $\Delta G^{\mathrm{o}}$ values were slightly affected by temperature but not $\mathrm{pH}$-dependent. 
CONFLICT OF INTEREST

None declared. 


\section{REFERENCES}

1. Thoma, J. A., Spradlin, J. E., and Dygert, S. (1971) Plant and animal amylases in The Enzymes (Boyer, P.D., ed.) pp. 115-189, Academic Press, New York

2. Janeček, Š., and Ševčík, J. (1999) The evolution of starch-binding domain. FEBS Lett.456, 119-125

3. Kato, M., Hiromi, K., and Morita, Y. (1974) Purification and kinetic studies of wheat bran $\beta$-amylase. Evaluation of subsite affinities. J. Biochem.75, 563-576

4. Suganuma, T., Ohnishi, M., Hiromi, K., and Morita, Y. (1980) Evaluation of subsite affinities of soybean beta-amylase by product analysis. Agric. Biol. Chem. 44, 1111-1117

5. Oyama, T., Miyake, H., Kusunoki, M., and Nitta, Y. (2003) Crystal structures of $\beta$-amylase from Bacillus cereus var. mycoides in complexes with substrate analogs and affinity-labeling reagents. $J$.

Biochem. 133, 467-474

6. Mikami, B., Adachi, M., Kage, T., Sarikaya, E., Nanmori, T., Shinke, R., and Utsumi, S. (1999) Structure of raw starch-digesting Bacillus cereus $\beta$-amylase complexed with maltose. Biochemistry 38, 7050-7061

7. Nomura, K., Mikami, B., and Morita, Y. (1986) Interaction of soybean $\beta$-amylase with glucose. $J$. Biochem. 100, 1175-1183 
8. Kang, Y.-N., Tanabe, A., Adachi, M., Utsumi, S., and Mikami, B. (2005) Structural analysis of threonine 342 mutants of soybean $\beta$-amylase: role of a conformational change of the inner loop in the catalytic mechanism. Biochemistry 44, 5106-5116

9. Nitta, Y., Isoda,Y., Toda, H., and Sakiyama, F. (1989) Identification of glutamic acid 186 affinity-labeled by 2, 3-epoxypropyl $\alpha$-D-glucopyranoside in soybean $\beta$-amylase. J. Biochem. 105, 573-576

10. Lizotte, P. A., Henson, C. A., and Duke, S. H. (1990) Purification and characterization of pea epicotyl $\beta$-amylase. Plant Physiol. 92, 615-621

11. Thoma, J. A., and Koshland, D. E. Jr. (1960) Competitive inhibition by substrate during enzyme action. Evidence for the induced-fit theory. J. Am. Chem. Soc. 82, 3329-3333

12. Marshall, J. J. (1973) On the interaction of $\beta$-amylase with substrate and inhibitors, with comments on Koshland's induced-fit hypothesis. Eur. J. Biochem. 33, 494-499

13. Daba, T., Kojima, K., and Inouye, K. (2013) Kinetic and thermodynamic analysis of the inhibitory effects of maltose, glucose, and related carbohydrates on wheat $\beta$-amylase. Enzyme Microb. Technol. 52, $251-257$

14. Daba, T., Kojima, K., and Inouye, K. (2012) Characterization and solvent engineering of wheat $\beta$-amylase for enhancing its activity and stability. Enzyme Microb. Technol. 51, 245-251

15. Oneda, H., Lee, S., and Inouye, K. (2004) Inhibitory effect of $0.19 \alpha$-amylase inhibitor from wheat kernel on the activity of porcine pancreas $\alpha$-amylase and its thermal stability. J. Biochem. 135, 421-427 
16. Narita, Y., and Inouye, K. (2011) Inhibitory effects of chlorogenic acids from green coffee beans and cinnamate derivatives on the activity of porcine pancreas $\alpha$-amylase isozyme I. Food Chem. 127, 1532-1539

17. Oneda, H., and Inouye, K. (2004) Detection of antigen-antibody reaction using a fluorescent probe and its application to homogeneous competitive-type immunoassay for insulin. Biosci. Biotechnol. Biochem. 68, 2190-2192

18. Ohnishi, M., Yamashita, T., and Hiromi, K. (1977) Static and kinetic studies by fluorometry on the interaction between gluconolactone and glucoamylase from Rh. niveus. J. Biochem. 8, 99-105

19. Fujiwara, K., Inouye, K., Tonomura, B., Murao, S., and Tsuru, D. (1977) Interaction of thiolsubtilisin with Streptomyces subtilisin inhibitor, SSI. J. Biochem. 82, 125-130

20. Hanes, C. S. (1932) Studies on plant amylases. The effect of starch concentration upon the velocity of hydrolysis by the amylase of germinated barley. Biochem. J. 26, 1406-1421

21. Horn, J. R., Russell, D., Lewis, E. A., and Murphy, K. P. (2001) van’t Hoff and calorimetric enthalpies from isothermal titration calorimetry: are there significant discrepancies? Biochemistry 40, 1774-1778

22. Posner, R. G., and Dix, J. A. (1985) Temperature dependence of anion transport inhibitor binding to human red cell membranes. Biophys. Chem. 23, 139-145

23. Rothfus, J. A., and Kennel, S. J. (1970) Properties of wheat beta-amylase adsorbed on glutenin. Cereal Chem. 47, 140-146 
24. Wagner, G., Haeger, K.-P., and Ziegler, P. (1996) Nucleotide sequence of a cDNA from wheat leaves encoding ubiquitous $\beta$-amylase (accession no. X98504) (PGR 96-123). Plant Physiol. 112, 1735-1736

25. Kunikata, T., Yamano, H., Nagamura, T., and Nitta, Y. (1992) Study on the interaction between soybean $\beta$-amylase and substrate by the stopped-flow method. J. Biochem. 112, 421-425

26. Mikami, B., Nomura, K., and Morita, Y. (1983) Interaction of native and SH-modified $\beta$-amylase of soybean with cylohexadextrin and maltose. J. Biochem. 94, 107-113

27. Sasaki, M., Matsuo, I., and Fujita, H. (1991) Hydrophobicity-dependent fluorescence properties and intracellular fluorospectroscopic behavior of phototoxic drugs. Photochem. Photobiol. 53, 385-389

28. Altschul, S. F., Gish, W., Miller, W., Myers, E. W., and Lipman, D. J. (1990) Basic local alignment search tool. J. Mol. Biol. 215, 403-410

29. Femi-Ola, T. O., Oshokoya, A. H., and Bamidele, O. S. (2013) Kinetic properties of beta-amylase from Bacillus subtilis. IOSR-JESTFT 2, 19-23

30. Yoshigi, N., Okada, Y., Maeba, H., Sahara, H., Tamaki, T. (1995) Construction of a plasmid used for the expression of a sevenfold-mutant barley $\beta$-amylase with increased thermostability in Escherichia coli and properties of the sevenfold-mutant $\beta$ - amylase. J. Biochem. 118, 562-567 
31. Arnold, K., Bordoli, L., Kopp, J., and Schwede, T. (2006). The SWISS-MODEL Workspace: A web-based environment for protein structure homology modelling. Bioinformatics 22, 195-201

32. Hiromi, K., Nitta, Y., Numata, C., and Ono, S. (1973) Subsite affinities of glucoamylase: examination of the validity of the subsite theory. Biochim. Biophys. Acta 302, 362-375

33. Mikami, B., Yoon, H.-J., and Yoshigi, N. (1999) The crystal structure of the sevenfold mutant of barley $\beta$-amylase with increased thermostability at $2.5 \AA$ A resolution. J. Mol. Biol. 285, 1235-1243

34. Kitagishi, K., Hiromi, K., Oda, K., and Murao, S. (1983) Equilibrium study on the binding between thermolysin and streptomyces metalloprotease inhibitor, talopeptin (MKI). J. Biochem. 93, 47-53

35. Niku-Paavola, M.-L., Nummi, M., Kachkin, A., Daussant, J., and Enari, T.-M. (1972) The isoelectric focusing electrophoresis of wheat $\beta$-amylases. Cereal Chem. 49, 580-585

36. Nitta, Y., Kunikata, T., and Watanabe, T. (1979) Kinetic study of soybean $\beta$-amylase. The effect of pH. J. Biochem. 85, 41-45

37. Tanaka, A., Ohnishi, M., Hiromi, K., Miyata, S., and Murao, S. (1982) Static and kinetic studies on the binding of Streptomyces trehalase inhibitor SGI with Rhizopus glucoamylase. Comparison with glucose and gluconolactone. J. Biochem. 91, 1-9 
Table 1. The temperature-dependence of the association constant $\left(K_{\mathrm{a}}\right)$ and thermodynamic parameters of maltose and glucose binding to WBA.

\begin{tabular}{ccccccc}
\hline & Temperature $(\mathrm{K})$ & $K_{\mathrm{d}}(\mathrm{M})$ & $K_{\mathrm{i}}(\mathrm{M}) *$ & $K_{\mathrm{a}}\left(\mathrm{M}^{-1}\right)$ & $\Delta G^{\mathrm{o}}\left(\mathrm{kJ} \mathrm{mol}^{-1}\right)$ & $T \Delta S^{0}\left(\mathrm{~kJ} \mathrm{~mol}^{-1}\right)$ \\
\hline \multirow{3}{*}{ Maltose } & 298 & $0.2 \pm 0.1$ & $0.1 \pm 0.0$ & $5.0 \pm 1.1$ & $-4.0 \pm 0.8$ & $-20.3 \pm 3.3$ \\
& 308 & $0.3 \pm 0.1$ & $0.1 \pm 0.0$ & $3.2 \pm 0.8$ & $-2.9 \pm 0.5$ & $-21.4 \pm 4.3$ \\
& 318 & $0.4 \pm 0.1$ & $0.2 \pm 0.0$ & $2.7 \pm 0.9$ & $-2.5 \pm 0.8$ & $-21.9 \pm 4.8$ \\
\hline \multirow{3}{*}{ Glucose } & 298 & $0.4 \pm 0.1$ & $0.3 \pm 0.0$ & $2.8 \pm 0.9$ & $-2.5 \pm 0.9$ & $-7.2 \pm 1.0$ \\
& 308 & $0.4 \pm 0.2$ & $0.4 \pm 0.1$ & $2.4 \pm 0.9$ & $-2.2 \pm 0.7$ & $-7.5 \pm 1.4$ \\
& 318 & $0.5 \pm 0.1$ & $0.4 \pm 0.0$ & $2.2 \pm 0.7$ & $-1.9 \pm 0.7$ & $-7.8 \pm 1.3$ \\
\hline
\end{tabular}

*cited from reference (13)

The experiment was conducted at various temperatures at $\mathrm{pH} 5.4$, and the initial enzyme concentration [E]。 was $0.2 \mu \mathrm{M}$. The $\Delta H^{\circ}$ values obtained from the van't Hoff plots were $-24.3 \pm 3.2 \mathrm{~kJ} \mathrm{~mol}^{-1}$ for maltose and $-9.7 \pm 2.5 \mathrm{~kJ} \mathrm{~mol}^{-1}$ for glucose binding to WBA. The values are mean $\pm \mathrm{SD}$, each experiment was done in triplicates. 
Table 2. The $\mathbf{p H}$-dependence of the association constant $\left(K_{\mathrm{a}}\right)$ and change in Gibbs energy $\left(\Delta G^{0}\right)$ of maltose and glucose binding to WBA.

\begin{tabular}{lccccc}
\hline & $\mathrm{pH}$ & $K_{\mathrm{d}}(\mathrm{M})$ & $K_{\mathrm{i}}(\mathrm{M})^{*}$ & $K_{\mathrm{a}}\left(\mathrm{M}^{-1}\right)$ & $\Delta G^{\mathrm{o}}\left(\mathrm{kJ} \mathrm{mol}^{-1}\right)$ \\
\hline \multirow{3}{*}{ Maltose } & 3.0 & $0.2 \pm 0.1$ & $0.1 \pm 0.0$ & $4.6 \pm 0.6$ & $-3.8 \pm 0.8$ \\
& 5.4 & $0.2 \pm 0.1$ & $0.2 \pm 0.0$ & $5.0 \pm 0.8$ & $-4.0 \pm 0.8$ \\
& 9.0 & $0.2 \pm 0.0$ & $0.1 \pm 0.0$ & $5.9 \pm 1.0$ & $-4.4 \pm 0.9$ \\
\hline \multirow{3}{*}{ Glucose } & 3.0 & $0.3 \pm 0.1$ & $0.3 \pm 0.0$ & $3.5 \pm 0.9$ & $-3.1 \pm 0.7$ \\
& 5.4 & $0.3 \pm 0.1$ & $0.4 \pm 0.0$ & $2.8 \pm 1.1$ & $-2.5 \pm 0.7$ \\
& 9.0 & $0.3 \pm 0.1$ & $0.2 \pm 0.0$ & $3.9 \pm 1.0$ & $-3.3 \pm 0.6$ \\
\hline
\end{tabular}

* cited from reference (13)

The experiment was conducted at various $\mathrm{pH}$ at $25^{\circ} \mathrm{C}$ and the initial enzyme concentration [E]。 was $0.2 \mu \mathrm{M}$.

The experiments were done in triplicates and the values are mean \pm SD. 


\section{FIGURE LEGENDS}

Fig. 1. The effects of increasing concentrations of maltose $0-1.4 \mathrm{M}(\mathrm{A})$ and glucose $0-2.8 \mathrm{M}(\mathrm{B})$ on the fluorescence of WBA. The initial concentration of WBA was $0.2 \mu \mathrm{M}$. The fluorescence intensity of WBA was partially quenched up on titration with increasing concentrations of maltose or glucose at $25^{\circ} \mathrm{C}$, pH 5.4 and $\lambda_{\mathrm{ex}}=280 \mathrm{~nm}$.

Fig. 2. The change in fluorescence intensity $(\Delta F)$ of WBA with increasing concentrations of maltose and glucose (A). Hanes-Woolf plots of the change in WBA fluorescence $(\Delta F)$ with increasing concentrations of maltose and glucose (B). The markers in both plots are for maltose (O) and for glucose ( $\square) . K_{\mathrm{d} 1}$ is the $K_{\mathrm{d}}$ value of maltose at lower concentration and $K_{\mathrm{d} 2}$ at higher concentration. The experiment was conducted in triplicates at $25^{\circ} \mathrm{C}, \mathrm{pH} 5.4$ at $\lambda_{\mathrm{ex}}=280 \mathrm{~nm}$.

Fig. 3. The fluorescence intensity of WBA with excitation at $280 \mathrm{~nm}$ ( - ) and at $295 \mathrm{~nm}(\cdots-\cdots)$ in panel A. The fluorescence of WBA excited at $295 \mathrm{~nm}$ in the absence of inhibitors ( - ), in the presence of $1.4 \mathrm{M}$ maltose (......) and 2.8 M glucose (---) in panel B. The initial concentration of WBA was $0.2 \mu \mathrm{M}$ and the experiment was conducted at $25^{\circ} \mathrm{C}, \mathrm{pH} 5.4$.

Fig. 4. The change in fluorescence intensity $(\Delta F)$ of WBA with increasing concentrations of maltose and glucose (A). Hanes-Woolf plots of the change in WBA fluorescence $(\Delta F)$ with increasing concentrations of maltose and glucose (B). The markers in the plots are for maltose (O) and for glucose $(\square)$. The experiment was done in triplicates at $25^{\circ} \mathrm{C}, \mathrm{pH} 5.4$, at $\lambda_{\mathrm{ex}}=295 \mathrm{~nm}$. 
Fig. 5. Hanes-Woolf plots of maltose $(\mathrm{O})$ and glucose $(\square)$ quenching the fluorescence of WBA at $35^{\circ} \mathrm{C}$ (Panel A), and at $45^{\circ} \mathrm{C}$ (Panel B) at pH 5.4 at $\lambda_{\text {ex }}=280 \mathrm{~nm}$. The Hanes-Woolf plot at $25^{\circ} \mathrm{C}, \mathrm{pH} 5.4$ was presented in Fig. 2B. The $K_{d}$ values of maltose and glucose were obtained from the x-intercepts of the linear equations. The linear plots are independent for glucose and maltose under similar temperature and $\mathrm{pH}$ conditions; the graphs do not show type of inhibition.

Fig. 6. van't Hoff plots of maltose and glucose quenching the fluorescence of WBA with increasing temperature at $\mathrm{pH} 5.4$ at $\lambda_{\mathrm{ex}}=280 \mathrm{~nm}$. The markers in the plots are for maltose (O) and for glucose ( $\square$ ). The standard enthalpy changes $\left(\Delta H^{\circ}\right)$ of WBA binding maltose or glucose were obtained from the slope of the linear equations (slope $=-\Delta H^{\circ} / R$ ). The values of $\Delta H^{\circ}$ were $-24.3 \pm 3.2 \mathrm{~kJ} \mathrm{~mol}^{-1}$ for maltose and $-9.7 \pm 2.5 \mathrm{~kJ} \mathrm{~mol}^{-1}$ for glucose.

Fig. 7. The Hanes-Woolf plots of maltose and glucose quenching the fluorescence of WBA at pH 3.0 (Panel A) and at $\mathrm{pH} 9.0$ (Panel B) at $25^{\circ} \mathrm{C}$ at $\lambda_{\mathrm{ex}}=280 \mathrm{~nm}$. The Hanes-Woolf plot at $\mathrm{pH} 5.4,25^{\circ} \mathrm{C}$ was presented in Fig. 2B. The markers in the plots are for maltose $(\mathrm{O})$ and for glucose ( $\square$ ). The $\mathrm{x}$-intercepts of the linear equations give $-K_{d}$ values in this study. 


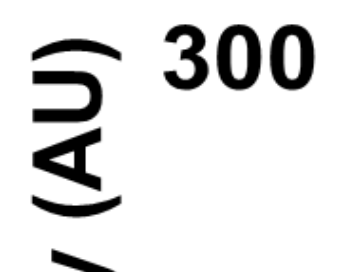

Kyoto University Research Information Repository



\section{Top}

Wavelength (nm)

介

Fig. 1A 



\section{Top}

$\Uparrow$

Fig. 1B 




Top

$\Uparrow$

Fig. 2A 


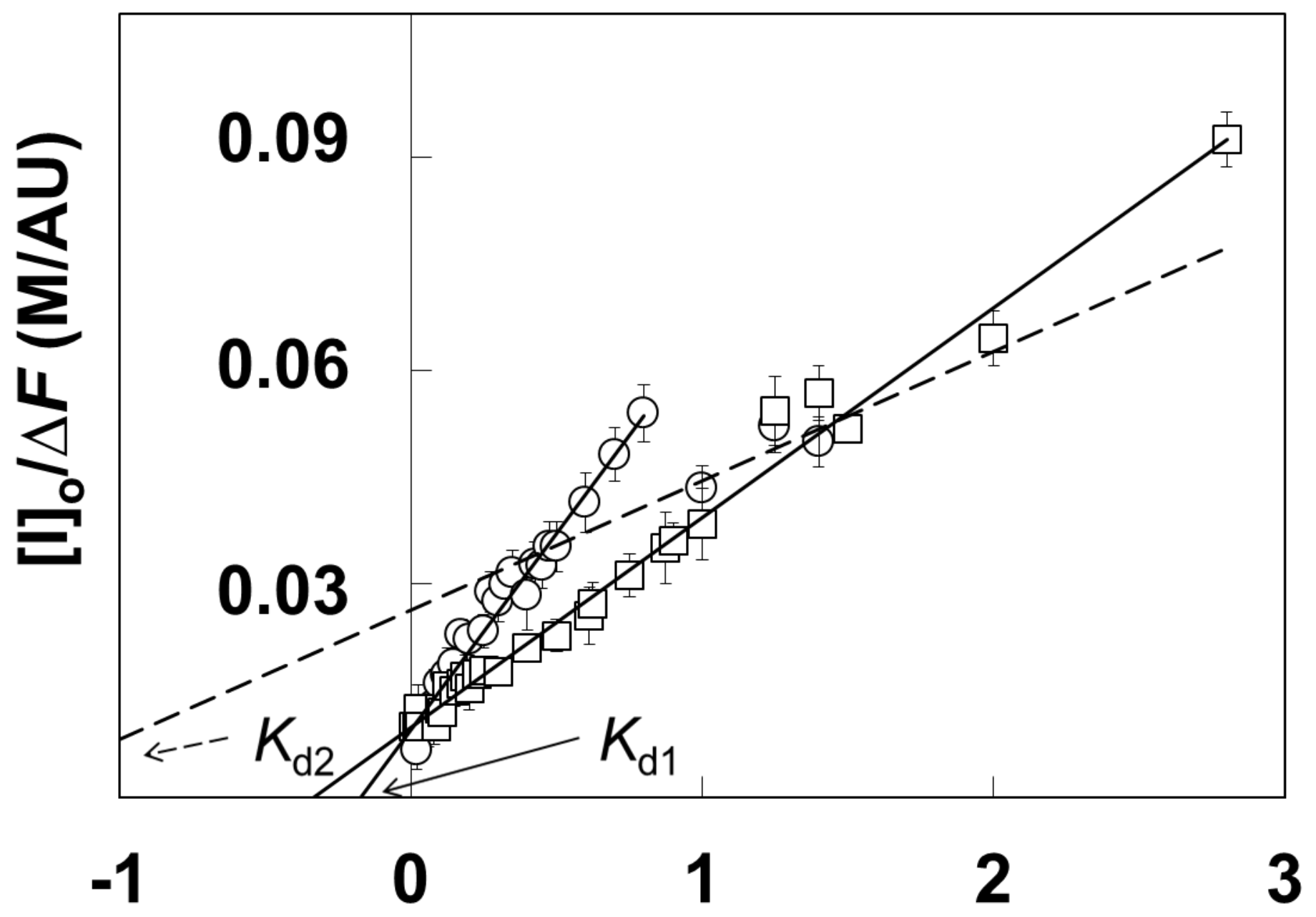

Top

$\Uparrow$

[l] (M)

Fig. 2B 


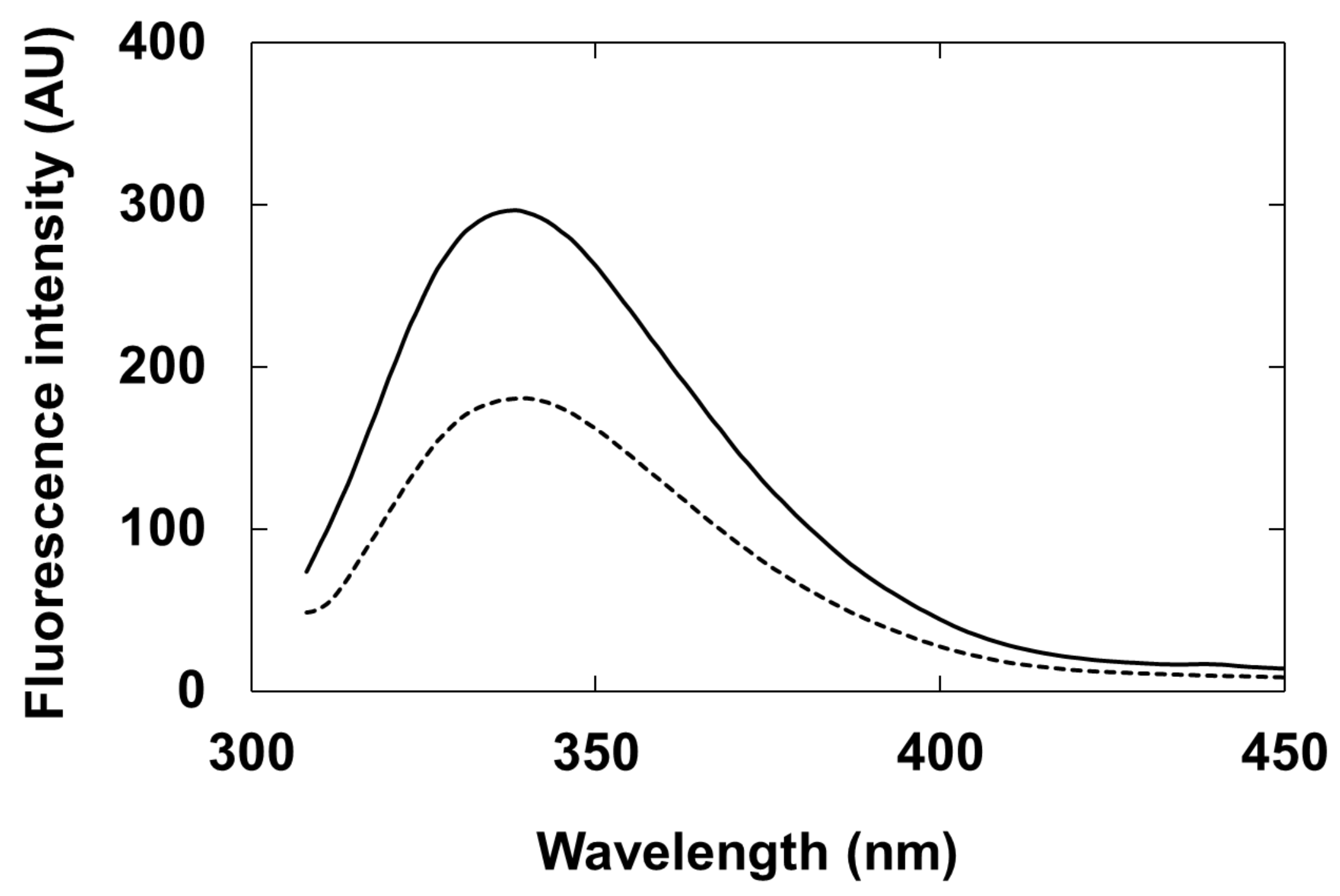

Top

$\Uparrow$

Fig. 3A 


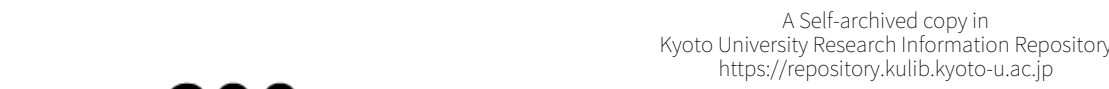

KURENAII II

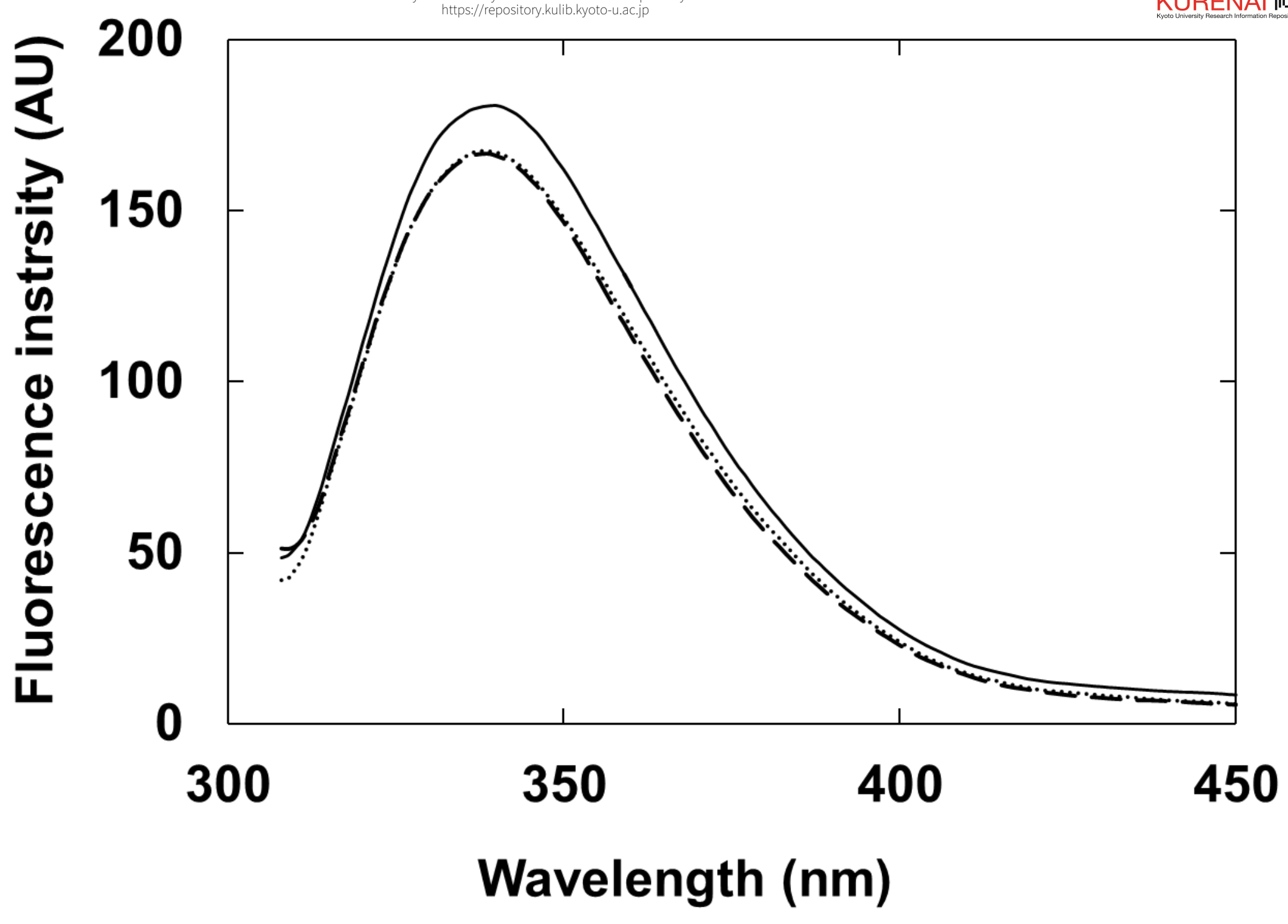

\section{Top}

介

Fig. 3B 


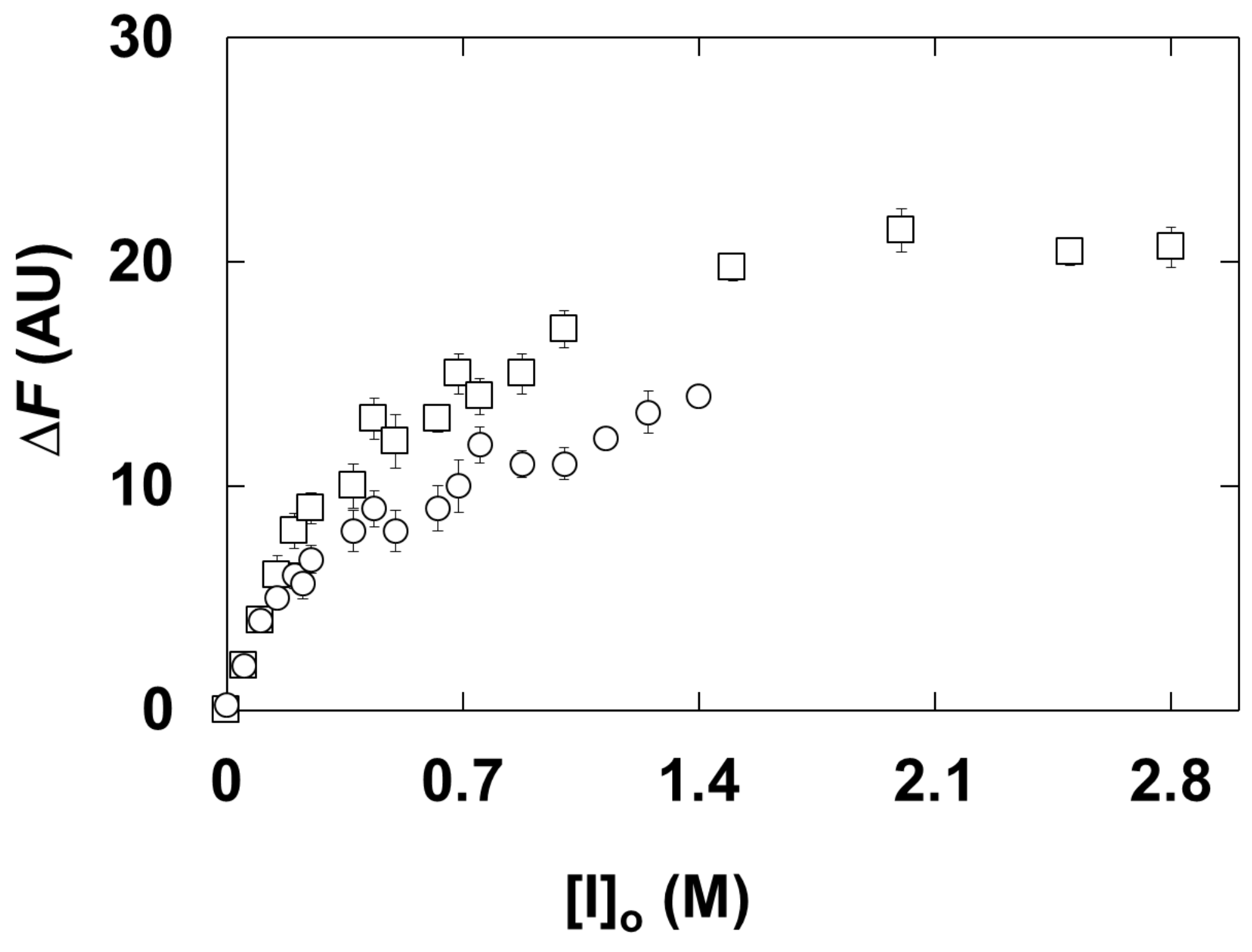

Top

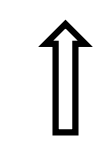

[I]。 (M)

Fig. 4A 




Top

$\Uparrow$

$[\mathrm{l}]_{\mathrm{o}}(\mathrm{M})$

Fig. 4B 


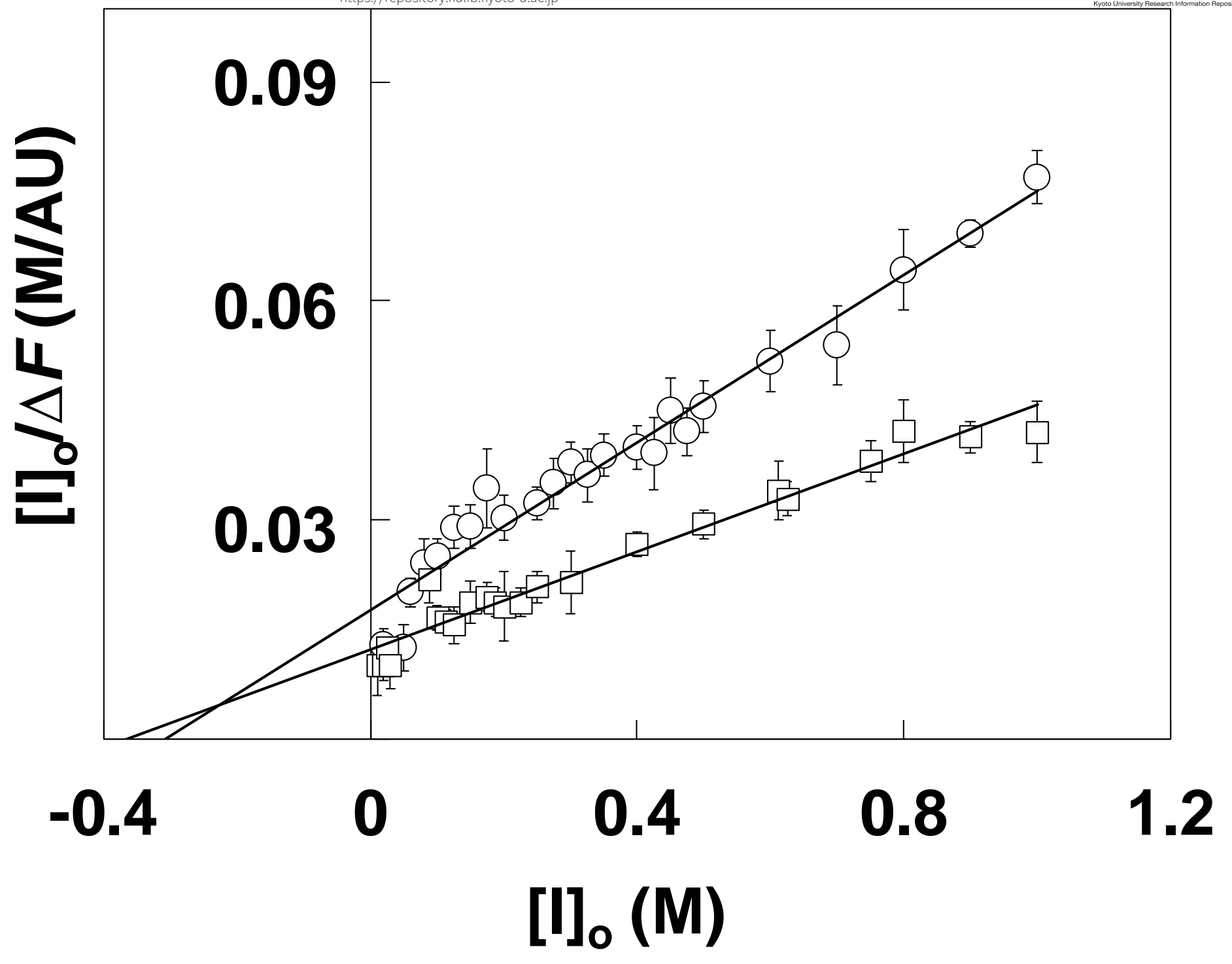

Top

$\Uparrow$

Fig. 5A 


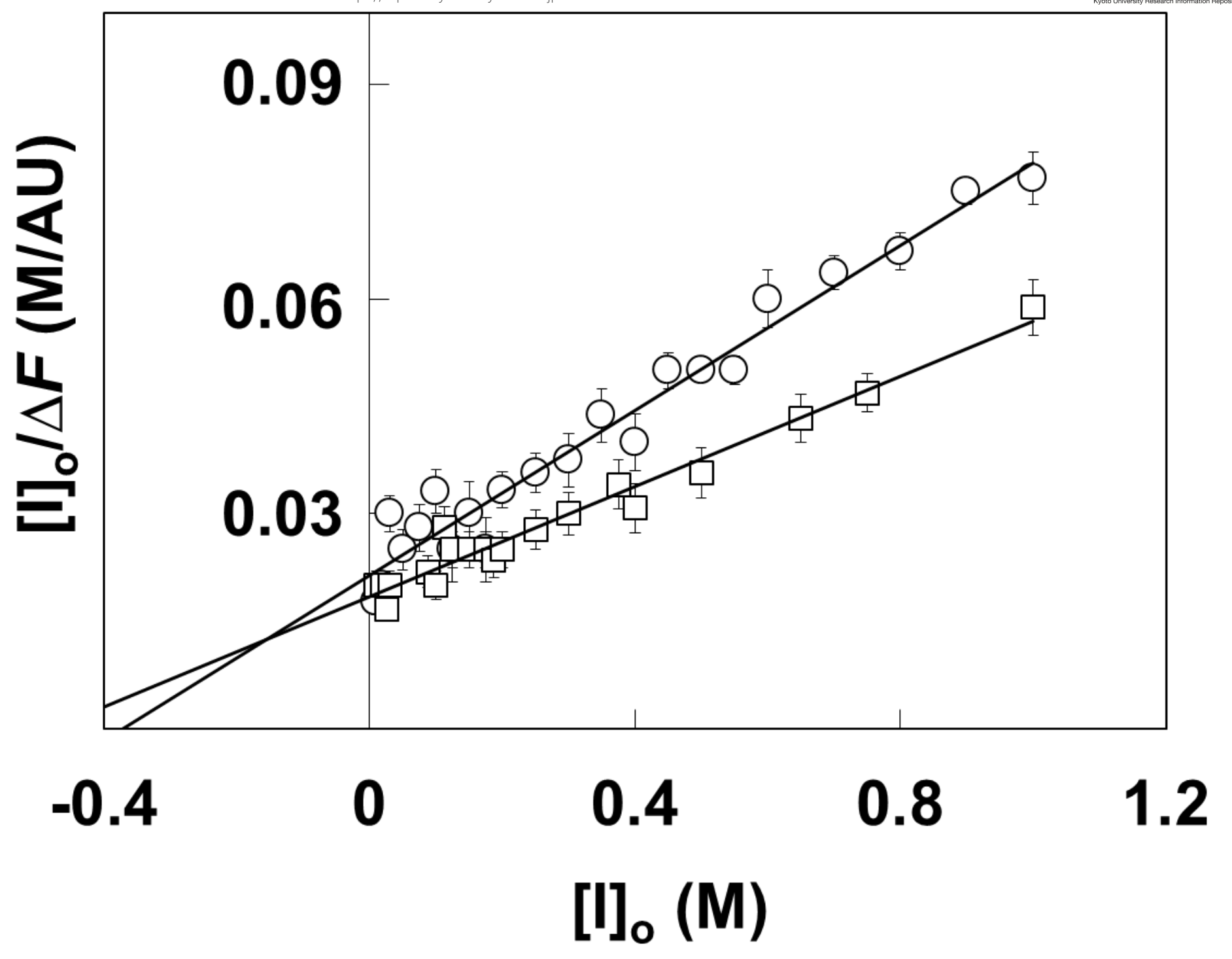

Top

$\Uparrow$

Fig. 5B 




Top

$\hat{\imath}$

Fig. 6 


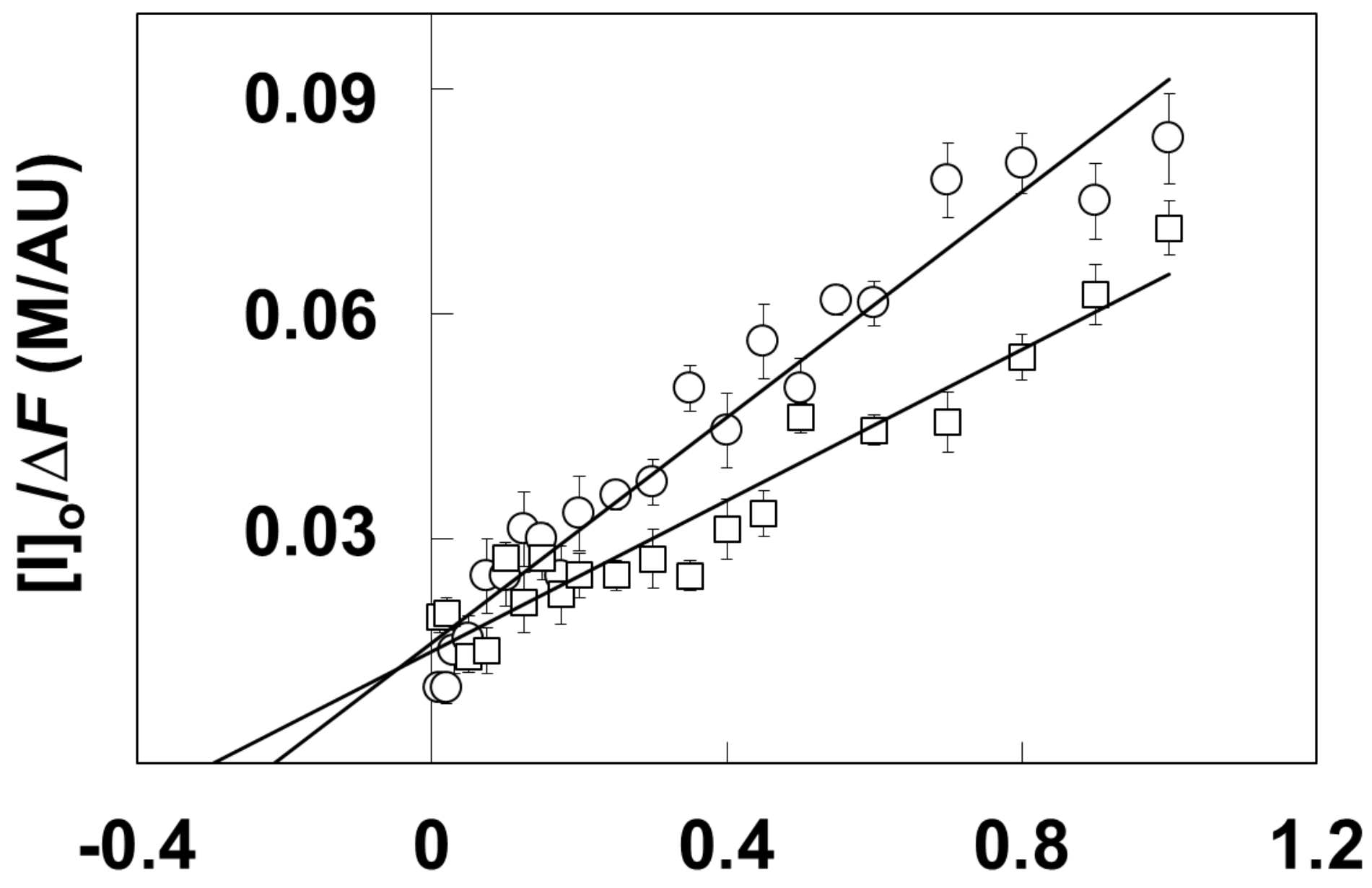

Top

$\Uparrow$

[I]。 (M)

Fig. 7A 


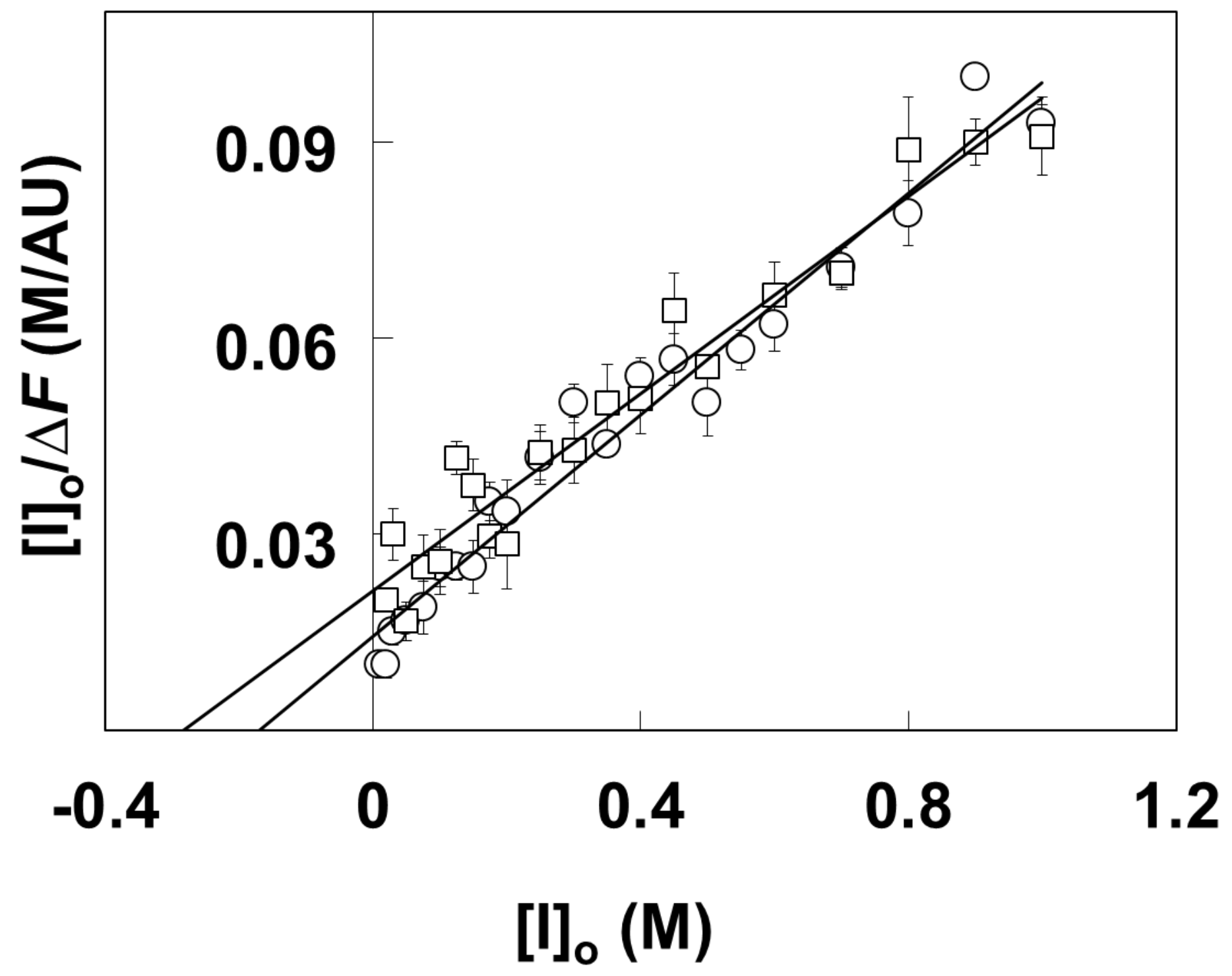

Top

$\Uparrow$

Fig. 7B 